\title{
THE EFFECT OF FOSSIL FUEL AND HYDROPOWER ON CARBON DIOXIDE EMISSIONS: EKC VALIDATION WITH STRUCTURAL BREAKS
}

\author{
Chenxia XIA*, Zilong WANG \\ College of Economics and Management, Nanjing University of Aeronautics and Astronautics, \\ 211106, Nanjing, China
}

Received 13 April 2019; accepted 15 November 2019

\begin{abstract}
This research is carried out to explore the relationship between economic growth, fossil energy, carbon emissions, hydropower, industrial development and energy endowment, and the effectiveness of the environmental Kuznets curve (EKC) hypothesis in China from 1965 to 2016 is tested. To this end, some econometric methods with structural breaks are employed. The results illustrate that the EKC considering structural breaks is existed in China. Furthermore, hydropower consumption can significantly reduce carbon dioxide $\left(\mathrm{CO}_{2}\right)$ emissions, however, the reduction can be masked by the increase of fossil energy consumption. In addition, industrialization level and economic growth positively and significantly affect $\mathrm{CO}_{2}$ emissions. Finally, some policies for reducing $\mathrm{CO}_{2}$ emissions are put forward.
\end{abstract}

Keywords: hydropower, Environmental Kuznets curve, structural breaks, $\mathrm{CO}_{2}$ emissions, fossil fuel, Granger causality.

\section{Introduction}

China is now facing the challenges of fostering economic growth and dealing with energy and environmental problems (C. Dong, X. Dong, Jiang, K. Dong, \& Liu, 2018). China has consumed a lot of energy in the past decades. From 1965 to 2016, the total amount of energy consumption in China showed a rising trend, and began to rise sharply in 2003. In 1965, China's energy consumption was 131.5 million tonnes oil equivalent (Mtoe), of which fossil fuels make up 96\% (Figure 1). In 2016, China's energy consumption reached 3047.2 Mtoe, of which fossil energy consumption accounted for $84 \%$. Although fossil energy consumption has declined, it is still the main energy source. Fossil energy is the major source of carbon emissions, with 489 million tonnes of emissions in 1965 and 9123 million tonnes in 2016, accounting for $27.23 \%$ of the world's carbon emissions (formerly British Petroleum [BP], 2018). With the process of industrialization and urbanization, the main sources of energy consumption have gradually shifted to oil and natural gas. Oil consumption was 11.1 Mtoe, accounting for $13 \%$ of total energy consumption in 1965, and it soared to 587.2 Mtoe in 2016. China's natural gas consumption amounted to 0.95 Mtoe in 1965, and increased to 180.1 Mtoe in 2016 (Figure 1).

Inevitably, massive pollutants are caused for the increase of fossil energy consumption. China released
9232.6 million tonnes of $\mathrm{CO}_{2}$ with the share $27.6 \%$ of the total in 2017 (BP, 2018). Low-carbon economy is a means to deal with environmental problems and energy threats, and provides direction for economic development (Kousksou et al., 2015). The core of low-carbon economy is the type of energy applied. Under this circumstance, the development and utilization of renewable energy has been gradually popularized. The use of renewable energy is a viable means of achieving a real green economy with the advantages of accessibility and sustainability (Gasparatos, Doll, Esteban, Ahmed, \& Olang, 2017). A mix of renewable and fossil energy can balance economic, social and environmental development. Consequently, renewable energy is applied as a useful substitute to fossil fuels (Bhattacharya, Churchill, \& Paramati, 2017). Hydropower is the dominated renewable energy. Specifically, the hydropower consumption in China was 5 Mtoe in 1965 and 260.96 Mtoe in 2016, which has grown almost 72 times (Figure 1). Thence, along with the enormous requirements of hydropower and the increase of $\mathrm{CO}_{2}$, it is of great significance to better understand the nexus between hydropower and $\mathrm{CO}_{2}$ to make policy for tackling $\mathrm{CO}_{2}$.

Given the deteriorating air quality and the increasingly exhausted fossil energy, many researchers have analyzed the nexus between hydropower energy and $\mathrm{CO}_{2}$. For instance, Mohamed, Jebli, and Youssef (2019) studied the nexus between renewable energy, fossil energy and

*Corresponding author. E-mail: xiachenxia@nuaa.edu.cn 
terrorism from 1980 to 2015. Renewable energy Granger caused terrorism, as well as terrorism Granger caused trade openness. Zhang, B. Wang, and Z. Wang (2017) applied autoregressive distributed lag model (ARDL), vector error correction model (VECM) and fully modified ordinary least squares (FMOLS) models to study the relation between energy and $\mathrm{CO}_{2}$ emissions in Pakistan from 1970 to 2012. The research results showed that renewable energy can effectively reduce carbon emissions. Liu, Zhang, and Bae (2017) studied the effect of renewable energy and agricultural added-value on $\mathrm{CO}_{2}$ emissions from 1970 to 2013. The results showed that renewable energy was negatively related to $\mathrm{CO}_{2}$, and non-renewable energy was positively correlated with $\mathrm{CO}_{2}$. Despite the nexus between hydropower energy and carbon emissions has been studied in regional and country level, based on the literature surveyed, little research has been done on the nexus between hydropower energy and $\mathrm{CO}_{2}$ in China.

The environmental Kuznets curve (EKC) is intended to analyze the relationship between economy and carbon emissions. The verification of EKC hypothesis is helpful to understand the nexus of energy-growth-pollutant. A majority of studies have been done to examine the EKC and these researches can be divided into two strands. The first strand proved that the EKC existed in inverted U-shaped or N-shaped. For example, Ulucak, and Bilgili (2018); Gill, Viswanathana, and Hassanb (2018); K. Dong, Sun, and X. Dong (2018); Danish, Zhang, B. Wang, and Z. Wang (2017); Bimonte and Stabile (2017) and Balado-Naves, Baños-Pino, and Mayor (2018) confirmed that EKC existed in some areas and presented inverted U-shaped or $\mathrm{N}$-shaped. Employed different countries, different data set or different time span, Shabani and Shahnazi (2019); Kasman and Duman (2015); Bekhet and Othman (2018); Seker, Ertugrul, and Cetin (2015) and Pata (2018) estimated the occurrence of EKC hypothesis. Another strand believed that China's EKC did not exist in some countries; economic growth and carbon emissions had a linear relationship (Dong, Wang, \& Guo, 2016; Ghaffar, Ashraf, Bashir, \& Cui, 2017; Muhammad, Mantu, Syed, \& Shawkat, 2019; Ngarambe, Lim, \& Kim, 2018). To date, as far as we know, no empirical studies have investigated the causal linkages among energy endowment, industrialization, economic development, $\mathrm{CO}_{2}$ emissions, hydropower consumption and fossil resources consumption in China by verifying the effectiveness of EKC. What's more, the econometric techniques used in former researches often overlook the existence of structural breaks, and it may cause unreliable results.

Given the above background, unit root tests, cointegration method and causality test with structural breaks are applied in this paper in order to analyze the linkages among energy endowment, economic development, industrialization, carbon emissions, hydropower consumption and fossil resources consumption in the EKC equation in China covering the period of 1965 to 2016.

The main contributions of this paper are as follows. First, the most recent data is applied in this research; this
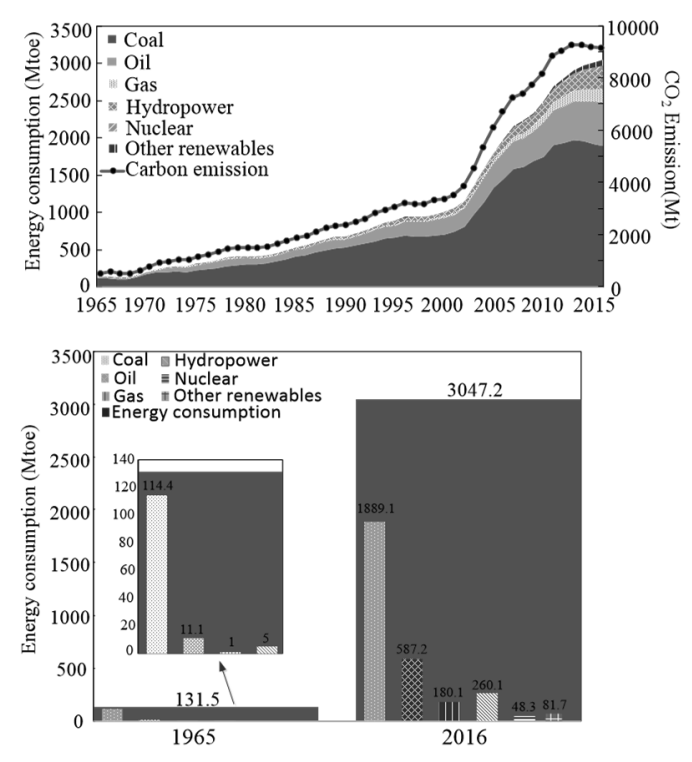

Figure 1. China's energy consumption and $\mathrm{CO}_{2}$ consumption from 1965 to 2016

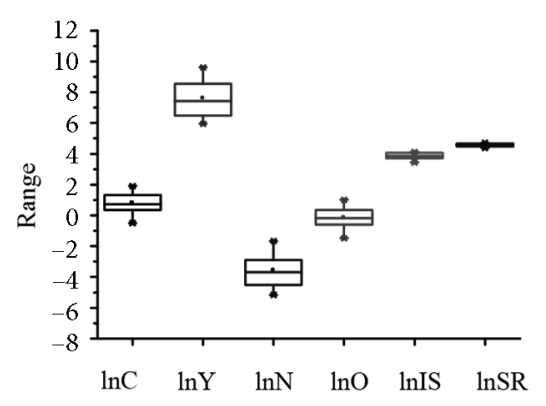

Figure 2. Box chart of all variables in this paper

helps to provide new results, thereby allowing policymakers to have a recent causal relation among the variables. Second, hydropower consumption is considered to be a driving force to reduce $\mathrm{CO}_{2}$ emissions in China, which can help the China's government make specific policies to tackle $\mathrm{CO}_{2}$ emissions, and the blank of common EKC studies in the context of China is filled. Third, unlike the prior literatures, which used traditional technique ignoring structural breaks, unit root tests and economic methods in this paper take structural breaks into account, which can offer more reliable results.

The sections of this paper are arranged as listed below. Section 1 describes the data sources, model building and estimation strategy. Section 2 is the analysis of empirical results. Section 3 is further discussion about the results. Last section is conclusion and policy implications.

\section{Econometric methodology}

\subsection{Variables and data sources}

The data covers the period from 1965 to 2016 in China. To eliminate the effect of price factors, per capita GDP is computed at constant prices $(1990=100)$, and all variables 
are processed logarithmically in this paper, so as to get rid of the effect of heteroscedasticity.

Before performing further analysis, an introduction of data sources and a description of the variables must be outlined. Figure 2 provides the distribution overlay of carbon emissions, energy endowment, economic growth, industrialization level, hydropower consumption and fossil energy consumption in China.

\subsubsection{Energy endowment}

According to Rafindadi and Ozturk (2016) and Bian and $\mathrm{Yu}$ (2019), energy endowment (SR) is estimated by the proportion of energy production to energy consumption. The data is from China Energy Statistical Yearbook (CESY, 2017). Energy endowment shows a steadily upward trend from 1965 to 1985, while it begins to decline from 1986.

\subsubsection{Industrialization level}

Following the approach applied in prior literatures (Haraguchi, Martorano, \& Sanfilippo, 2019; Li \& Lin, 2015), industrialization level (IS), measured in yuan and normalized to 1990 prices, refers to the value added of secondary industry in the proportion of GDP. The data is collected from China Statistical Yearbook (CSY). Industrialization level displays an upward trend between 1965 to 2016, implying that industrialization level is still in an accelerating process.

\subsubsection{Carbon emissions}

Carbon emissions (C) in this paper is measured by per capita carbon emissions. Notably, it is measured by the proportion of carbon emissions to total population. The data of carbon emissions is derived from BP (2018) and population is collected from CSY (2018). Carbon emissions demonstrate an upward trend over the period of 1965 to 2002, while it roars from 2003 to 2014. It follows a declining trend from 2015 to 2016.

\subsubsection{Economic growth}

The GDP and population used in economic growth (Y) are obtained from CSY (2018). It displays an upward trend.

\subsubsection{Hydropower consumption}

Hydropower consumption $(\mathrm{N})$ is measured by per capita hydropower consumption. Hydropower consumption and population are collected from CESY (2017) and CSY (2018), respectively. A steady upward trend is displayed between 1965 and 2003, and a sharp increasing trend follows from 2004 to 2016.

\subsubsection{Fossil energy consumption}

Fossil energy consumption $(\mathrm{O})$ is collected from CESY (2017). Fossil energy consumption increases sharply between 1965 and 2002; after that, it demonstrates an upward trend from 2003 to 2012. Compared with the former period, it increases slowly from 2013 to 2016. The descriptions of variables are presented in Table A3 of Appendix.

\subsection{The model}

Economic development affects carbon emissions by scale effect, structure effect and technology effect. Most studies of EKC only analyze the nexus between environmental pollution and economic growth, so the results will be unreliable for ignoring variables. In this paper, energy endowment, industrialization, hydropower consumption and fossil energy consumption are added to study the influences on environmental degradation.

The equation (1) and (2) showed the log-linear specification are modeled as following:

$\mathrm{N}$-EKC (hydropower consumption is applied in the EKC model) model:

$$
\begin{aligned}
& \ln C_{t}=\alpha_{1}+\alpha_{2} \ln Y_{t}+\alpha_{3} \ln Y_{t}^{2}+\alpha_{4} \ln S R_{t}+ \\
& \alpha_{5} \ln I S_{t}+\alpha_{6} \ln N_{t}+\alpha_{7} D_{1}+\alpha_{8} D_{2}+v_{t} .
\end{aligned}
$$

$\mathrm{O}-\mathrm{EKC}$ (fossil energy consumption is used in the EKC model) model:

$$
\begin{aligned}
& \ln C_{t}=\alpha_{1}+\alpha_{2} \ln Y_{t}+\alpha_{3} \ln Y_{t}^{2}+\alpha_{4} \ln S R_{t}+ \\
& \alpha_{5} \ln I S_{t}+\alpha_{6} \ln O_{t}+\alpha_{7} D_{1}+\alpha_{8} D_{2}+v_{t}
\end{aligned}
$$

where $D_{1}$ and $D_{2}$ are dummy variables, which capture the structural breaks. $v_{t}$ is error term with normal distribution. When $D_{1} \leq$ break date, $D_{1}=0$. When $D_{1}>$ break date, $D_{1}=1 . \alpha_{2}>0$ and $\alpha_{3}<0$ show that economic development has an inverted U-shaped relationship with $\mathrm{CO}_{2}$ emissions; this conforms the existence of EKC. $\alpha_{2}>0$ shows that carbon emissions rise with per capita GDP. $\alpha_{3}<0$ suggests that as the economy grows, carbon emissions gradually decrease.

\subsection{Estimation strategy}

Technically, the estimation strategy can be divided into four steps. First, based on the EKC hypothesis, two models of renewable energy and fossil energy are constructed, respectively. Second, we investigate the stationarity of all the time series, as well as estimate whether the structural breaks exist in variables or not. To achieve this, the unit root tests considering and not considering structural break are implemented. And then, in the two models, each variable is acted as an independent variable, the existence and short-term relationship of cointegration between variables are tested by the ARDL method with structural breaks. At last, the causal relationship of variables considering structural breaks is tested and the results are expected to contribute to the formulation of appropriate policies.

\subsubsection{Structural break unit root tests}

Unit root tests without structural breaks are utilized to test all variables. Hence, the Zivot-Andrews and Bai-Perron methods are applied to estimate the existence of structural breaks, and locate the breaks endogenously. The 
structural breaks are deeply studied by Bai and Perron, and the method of "endogenous structural breaks test" is put forward (Bai \& Perron, 2003). This method performs better in the case of small samples.

Supposing $m$ structural breaks are in a time length of $T$.

$$
\begin{aligned}
& y_{t}=x_{t}^{\prime} \beta+z_{t}^{\prime} \delta_{j}+u_{t} ; \\
& t=T_{j-1}+1, T_{j-2}+2, \ldots, T_{j}, j=1,2, \ldots, m+1,
\end{aligned}
$$

where $y_{t}$ is the interpreted variable, $\left(x_{t}\right)_{p \times 1}$ and $\left(z_{t}\right)_{q \times 1}$ are the explanatory variables, $\beta$ and $\delta_{j}$ are coefficients, $u_{t}$ is a random error term, $T_{1}, T_{2} \ldots, T_{m}$ are break dates, $m$ is the frequency of breaks, and $T$ is the samples. If $Y=\left(y_{1}, y_{2}, \ldots, y_{T}\right)^{\prime}, X=\left(x_{1}, x_{2}, \ldots, x_{T}\right)^{\prime}, U=\left(u_{1}, u_{2}, \ldots, u_{T}\right)^{\prime}$ and $\delta=\left(\delta_{1}{ }^{\prime}, \delta_{2}{ }^{\prime}, \ldots, \delta^{\prime}{ }_{m+1}\right)^{\prime}$, diagonal matrixes are $\bar{Z}=\operatorname{diag}\left(Z_{1}, Z_{2}, \ldots, Z_{m+1}\right) \quad$ and $\quad Z_{i}=\left(Z_{T_{i+1}+1}, \ldots, Z_{T_{i}}\right)^{\prime}$.

Solving out the equation (3) and calculating the sum of squares of residuals for each possible partition $\left(T_{1}, T_{2}\right.$, $\ldots, T_{m}$ ) is to get the minimum partition:

$$
\begin{aligned}
& \hat{T}_{1}, \hat{T}_{2}, \hat{T}_{3}, \ldots, \hat{T}_{m}= \\
& \arg \left[\min S_{T}\left(T_{1}, T_{2}, \ldots, T_{m}\right)\right] .
\end{aligned}
$$

Working out the above results, Bai-Perron came up with some testing methods to estimate the specific break dates. Sup wald test (Sup-F test) can be expressed by:

$$
\begin{aligned}
& F_{T}\left(\lambda_{1}, \lambda_{2}, \ldots, \lambda_{k}, q\right)= \\
& \frac{1}{T}\left|\frac{T-(K+1) q-p}{k p}\right| \bar{\delta}^{\prime} R^{\prime}\left(R \bar{V}(\bar{\delta}) R^{\prime}\right)^{-1} R \bar{\delta},
\end{aligned}
$$

where $\lambda_{i}=T_{i} / T, \quad(R \delta)^{\prime}=\left(\delta_{1}{ }^{\prime}-\delta_{2}{ }^{\prime}, \ldots, \delta_{k}{ }^{\prime}-\delta_{k+1}{ }^{\prime}\right) . \bar{V}(\bar{\delta})$ is a robust estimation of variance covariance matrix with autocorrelation and heteroscedasticity.

\subsubsection{ARDL bounds testing approach}

ARDL method is more robust for small sample (Pesaran, Shin, \& Smith, 2001). To achieve these objectives with robust results, we use the ARDL method with structural breaks.

The ARDL implies a single reduced-form equation. The ARDL model can be written as:

$$
\begin{aligned}
& \Delta \ln C_{t}=\beta_{0}+\sum_{i=1}^{a} \beta_{1 i} \Delta \ln C_{t-i}+\sum_{i=0}^{b} \beta_{2 i} \Delta \ln Y_{t-i}+ \\
& \sum_{i=0}^{c} \beta_{3 i} \Delta \ln Y_{t-i}^{2}+\sum_{i=0}^{d} \beta_{4 i} \Delta \ln S R_{t-i}+\sum_{i=0}^{e} \beta_{5 i} \Delta \ln I S_{t-i}+ \\
& \sum_{i=0}^{f} \beta_{6 i} \Delta \ln N_{t-i}+\delta_{0} \ln C_{t-1}+\delta_{1} \ln Y_{t-1}+\delta_{2} \ln Y_{t-1}^{2}+ \\
& \delta_{3} \ln S R_{t-1}+\delta_{4} \ln N_{t-1}+\delta_{5} \ln I S_{t-1}+\delta_{6} D_{1}+\delta_{7} D_{2}+\xi_{1 t} ;
\end{aligned}
$$

$$
\begin{aligned}
& \Delta \ln Y_{t}=\chi_{0}+\sum_{i=0}^{a} \chi_{1 i} \Delta \ln C_{t-i}+\sum_{i=1}^{b} \chi_{2 i} \Delta \ln Y_{t-i}+ \\
& \sum_{i=0}^{c} \chi_{3 i} \Delta \ln Y_{t-i}^{2}+\sum_{i=0}^{d} \chi_{4 i} \Delta \ln S R_{t-i}+\sum_{i=0}^{e} \chi_{5 i} \Delta \ln I S_{t-i}+ \\
& \sum_{i=0}^{f} \chi_{6 i} \Delta \ln N_{t-i}+\varphi_{0} \ln C_{t-1}+\varphi_{1} \ln Y_{t-1}+\varphi_{2} \ln Y_{t-1}^{2}+ \\
& \varphi_{3} \ln S R_{t-1}+\varphi_{4} \ln I S_{t-1}+\varphi_{5} \ln N_{t-1}+\varphi_{6} D_{1}+\varphi_{7} D_{2}+\xi_{2 t} ; \\
& \Delta \ln N_{t}=\mathfrak{l}_{0}+\sum_{i=0}^{a} \mathfrak{1}_{1 i} \Delta \ln C_{t-i}+\sum_{i=0}^{b} \mathfrak{1}_{2 i} \Delta \ln Y_{t-i}+ \\
& \sum_{i=0}^{c} \mathfrak{1}_{3 i} \Delta \ln Y_{t-i}^{2}+\sum_{i=0}^{d} \mathbf{l}_{4 i} \Delta \ln S R_{t-i}+\sum_{i=0}^{e} \mathfrak{1}_{5 i} \Delta \ln I S_{t-i}+ \\
& \sum_{i=1}^{f} \mathfrak{l}_{6 i} \Delta \ln N_{t-i}+\vartheta_{0} \ln C_{t-1}+\vartheta_{1} \ln Y_{t-1}+\vartheta_{2} \ln Y_{t-1}^{2}+ \\
& \vartheta_{3} \ln S R_{t-1}+\vartheta_{4} \ln I S_{t-1}+\vartheta_{5} \ln N_{t-1}+\vartheta_{6} D_{1}+\vartheta_{7} D_{2}+\xi_{3 t} ;
\end{aligned}
$$

$$
\begin{aligned}
& \Delta \ln I S_{t}=a_{0}+\sum_{i=0}^{a} a_{1 i} \Delta \ln C_{t-i}+\sum_{i=0}^{b} a_{2 i} \Delta \ln Y_{t-i}+ \\
& \sum_{i=0}^{c} a_{3 i} \Delta \ln Y_{t-i}^{2}+\sum_{i=0}^{d} a_{4 i} \Delta \ln S R_{t-i}+\sum_{i=1}^{e} a_{5 i} \Delta \ln I S_{t-i}+ \\
& \sum_{i=0}^{f} a_{6 i} \Delta \ln N_{t-i}+b_{0} \ln C_{t-1}+b_{1} \ln Y_{t-1}+b_{2} \ln Y_{t-1}^{2}+ \\
& b_{3} \ln S R_{t-1}+b_{4} \ln I S_{t-1}+b_{5} \ln N_{t-1}+b_{6} D_{1}+\xi_{4 t} ;
\end{aligned}
$$

$$
\begin{aligned}
& \Delta \ln S R_{t}=c_{0}+\sum_{i=0}^{a} c_{1 i} \Delta \ln c_{t-i}+\sum_{i=0}^{b} c_{2 i} \Delta \ln Y_{t-i}+ \\
& \sum_{i=0}^{c} c_{3 i} \Delta \ln Y_{t-i}^{2}+\sum_{i=1}^{d} c_{4 i} \Delta \ln S R_{t-i}+\sum_{i=0}^{e} c_{5 i} \Delta \ln I S_{t-i}+ \\
& \sum_{i=0}^{f} c_{6 i} \Delta \ln N_{t-i}+d_{0} \ln C_{t-1}+d_{1} \ln Y_{t-1}+d_{2} \ln Y_{t-1}^{2}+ \\
& d_{3} \ln S R_{t-1}+d_{4} \ln I S_{t-1}+d_{5} \ln N_{t-1}+d_{6} D_{1}+\xi_{5 t},
\end{aligned}
$$

where the meaning of each symbol in the formula is illustrated by the example of formula (3). Constant term is $\beta_{0}, \xi_{t}$ is white-noise error term, $\delta_{0,1,2,3,4,5,6,7}$ are the long-term coefficients. $a, b, c, d, e, f$ denote the optimal lag lengths confirmed by Schwarz-Bayesian criteria $(\mathrm{SBC})$ and Akaike information criteria (AIC). The null hypothesis is no cointegration, namely, $H_{0}: \beta_{0}=\delta_{0}=\delta_{1}=\delta_{3}=\delta_{4}=\delta_{5}=\delta_{6}=\delta_{7}$. Nevertheless, 
the alternative hypothesis is that cointegration exists, that is, $H_{1}: \beta_{0} \neq \delta_{0} \neq \delta_{1} \neq \delta_{3} \neq \delta_{4} \neq \delta_{5} \neq \delta_{6} \neq \delta_{7}$.

After cointegration nexus is determined, the long- and short-term linkages are to be further analyzed by ARDL method. The long-run effects among variables can be expressed as follows:

$$
\begin{aligned}
& \ln C_{t}=\eta_{0}+\sum_{i=1}^{a} \eta_{1 i} \ln C_{t-i}+\sum_{i=0}^{b} \eta_{2 i} \ln Y_{t-i}+ \\
& \sum_{i=0}^{c} \eta_{3 i} \ln Y_{t-i}^{2}+\sum_{i=0}^{d} \eta_{4 i} \ln S R_{t-i}+\sum_{i=0}^{e} \eta_{5 i} \ln I S_{t-i}+ \\
& \sum_{i=0}^{f} \eta_{6 i} \ln N_{t-i}+\eta_{7 i} D_{1}+\eta_{8 i} D_{2}+\mathrm{o}_{t} .
\end{aligned}
$$

The maximum lags in the equation are determined according to the optimal lags of the boundary test, and the long run relations among the series can be tested by the following equation:

$$
\begin{aligned}
& \ln C_{t}=\alpha_{0}+\alpha_{1} \ln C_{t}+\alpha_{2} \ln Y_{t}+ \\
& \alpha_{3} \ln Y_{t}^{2}+\alpha_{4} \ln S R_{t}+\alpha_{5} \ln I S_{t}+ \\
& \alpha_{6} \ln N_{t}+\alpha_{7} D_{1}+\alpha_{8} D_{2}+\mathrm{o}_{t},
\end{aligned}
$$

where the coefficients of the constant term, $D_{1}$ and $D_{2}$ are $\alpha_{0}=\eta_{0} /\left(1-\sum_{i=1}^{a} \eta_{1 i}\right), \quad \alpha_{7}=\eta_{7 i} /\left(1-\sum_{i=1}^{a} \eta_{1 i}\right)$, and $\alpha_{8}=\eta_{8 i} /\left(1-\sum_{i=1}^{a} \eta_{1 i}\right)$, respectively. $\ln Y_{t}$ is $\alpha_{2}=\sum_{i=0}^{b} \eta_{2 i} /\left(1-\sum_{i=1}^{a} \eta_{1 i}\right)$ and $\ln S R_{t}$ is $\alpha_{4}=\sum_{i=0}^{d} \eta_{4 i} /\left(1-\sum_{i=1}^{a} \eta_{1 i}\right)$

The error correction model (ECM) is established for analyzing short-term dynamics of the variables. The ECM model is as follows:

$$
\begin{aligned}
& \Delta \ln C_{t}=\lambda_{0}+\sum_{i=1}^{j} \lambda_{1 i} \Delta \ln C_{t-i}+\sum_{i=0}^{k} \lambda_{2 i} \Delta \ln Y_{t-i}+ \\
& \sum_{i=0}^{m} \lambda_{3 i} \Delta \ln Y_{t-i}^{2}+\sum_{i=0}^{n} \lambda_{4 i} \Delta \ln S R_{t-i}+\sum_{i=0}^{p} \lambda_{5 i} \Delta \ln I S_{t-i}+ \\
& \sum_{i=0}^{q} \lambda_{6 i} \Delta \ln N_{t-i}+\zeta E C T_{t-1}+\mathrm{u}_{t}
\end{aligned}
$$

where $\lambda_{0}$ signifies constant term, $\lambda_{1,2,3,4,5,6}$ denote short-run coefficients, $j, k, m, n, p, q$ denote optimal lag lengths and $E C T_{t}$ is error correction term. $\zeta$ signifies the velocity of long-term equilibrium modification.

\subsubsection{Granger causality}

Because the indexes are cointegrated, long-term and short-term causal relationships are to be explored. VECM Granger causality is utilized to detect the causal nexus between variables. The VECM method can be presented as:

$\left[\begin{array}{l}\ln C_{t} \\ \Delta \ln Y_{t} \\ \Delta \ln Y_{t}^{2} \\ \Delta \ln S R_{t} \\ \Delta \ln I S_{t} \\ \Delta \ln N_{t}\end{array}\right]=\left[\begin{array}{l}b_{1} \\ b_{2} \\ b_{3} \\ b_{4} \\ b_{5} \\ b_{6}\end{array}\right]+$

$\sum_{m=1}^{n}\left[\begin{array}{llllllll}d_{1,1, n} & d_{1,2, n} & d_{1,3, n} & d_{1,4, n} & d_{1,5, n} & d_{1,6, n} & d_{1,7, n} & d_{1,8, n} \\ d_{2,1, n} & d_{2,2, n} & d_{2,3, n} & d_{2,4, n} & d_{2,5, n} & d_{2,6, n} & d_{2,7, n} & d_{2,8, n} \\ d_{3,1, n} & d_{3,2, n} & d_{3,3, n} & d_{3,4, n} & d_{3,5, n} & d_{3,6, n} & d_{3,7, n} & d_{3,8, n} \\ d_{4,1, n} & d_{4,2, n} & d_{4,3, n} & d_{4,4, n} & d_{4,5, n} & d_{4,6, n} & d_{4,7, n} & d_{4,8, n} \\ d_{5,1, n} & d_{5,2, n} & d_{5,3, n} & d_{5,4, n} & d_{5,5, n} & d_{5,6, n} & d_{5,7, n} & d_{5,8, n} \\ d_{6,1, n} & d_{6,2, n} & d_{6,3, n} & d_{6,4, n} & d_{6,5, n} & d_{6,6, n} & d_{6,7, n} & d_{6,8, n}\end{array}\right] \times$

$\left(\begin{array}{l}\ln C_{t-n} \\ \Delta \ln Y_{t-n} \\ \Delta \ln Y_{t-n}^{2} \\ \Delta \ln S R_{t-n} \\ \Delta \ln I S_{t-n} \\ \Delta \ln N_{t-n}\end{array}\right)+\left(\begin{array}{l}\varsigma_{1} \\ \varsigma_{2} \\ \varsigma_{3} \\ \varsigma_{4} \\ \varsigma_{5} \\ \varsigma_{6}\end{array}\right) E C T_{t-1}+\left(\begin{array}{l}\xi_{1} \\ \xi_{2} \\ \xi_{3} \\ \xi_{4} \\ \xi_{5} \\ \xi_{6}\end{array}\right)$

where $(1-L)$ represents difference operator, $E C T_{t-1}$ is lagged residual. $T$-test is used to estimate the significance of $E C T_{t-1}$ coefficient, so as to signify the long run causality. The short-term causality between variables is tested by $F$-statistics.

\section{Results and discussion}

\subsection{Unit root tests considering and not considering structural breaks}

To apply any standard cointegration approach for examining the long-term nexus of the variables, the prime step is estimating the unit root properties. To achieve this, the Augmented Dickey-Fuller (ADF) and Phillips-Perron (PP) are utilized to explore the stability of these variables. The Dickey-Fuller Generalized Least Squares (DF-GLS) is also applied, since it can effectively improve the reliability of results with small samples. Table 1 presents outcomes of traditional unit root tests.

The outcomes show that all variables can reject the null hypothesis when these sequences are in their first differences, that is, all indexes are not stable.

These findings show that first differences of the indexes in this paper are I (1) at $1 \%$ and 5\% significance level, respectively. Therefore, cointegration estimation can be carried out by the bounds testing approach.

When structural breaks occur in data generating process, the test results may be spurious with PP or ADF test, 
Table 1. Traditional unit root tests

\begin{tabular}{|c|c|c|c|c|c|c|}
\hline \multirow{2}{*}{ Variable } & \multicolumn{3}{|c|}{ At level T-statistic } & \multicolumn{2}{c|}{ At 1st difference T-statistic } \\
\cline { 2 - 6 } & ADF & PP & DF-GLS & ADF & PP & DF-GLS \\
\hline $\ln C_{t}$ & $-2.459(4)$ & $-2.166(3)$ & $-2.479(4)$ & $-3.883(0)^{\star *}$ & $-3.870(3)^{\star *}$ & $-3.958(0)^{\star}$ \\
\hline $\ln Y_{t}$ & $-2.348(2)$ & $-3.114(3)$ & $-1.701(1)$ & $-5.267(0)^{\star}$ & $-5.147(3)^{\star}$ & $-5.217(0)^{\star}$ \\
\hline $\ln Y_{t}^{2}$ & $-2.863(1)$ & $-2.632(6)$ & $-1.202(1)$ & $-4.989(0)^{\star}$ & $-4.687(9)^{\star}$ & $-4.857(0)^{\star}$ \\
\hline $\ln N_{t}$ & $-2.412(0)$ & $-2.403(3)$ & $-1.724(0)$ & $-8.328(0)^{\star}$ & $-8.400(3)^{\star}$ & $-8.330(0)^{\star}$ \\
\hline $\ln O_{t}$ & $-1.848(0)$ & $-2.245(3)$ & $-1.865(0)$ & $-4.209(0)^{\star}$ & $-3.599(14)^{\star *}$ & $-4.296(0)^{\star}$ \\
\hline $\ln S R_{t}$ & $-1.969(0)$ & $-1.560(11)$ & $-1.431(0)$ & $-8.205(0)^{\star}$ & $-9.335(11)^{\star}$ & $-7.440(0)^{\star}$ \\
\hline $\ln I S_{t}$ & $-3.170(10)$ & $-1.882(0)$ & $-3.170(10)$ & $-5.306(0)^{\star}$ & $-5.187(6)^{\star}$ & $-4.854(0)^{\star}$ \\
\hline
\end{tabular}

Note: ${ }^{*}{ }^{* *}$ and ${ }^{* * *}$ indicate significant at the levels of $1 \%, 5 \%$ and $10 \%$.

which will not reject null hypothesis. Namely, ignoring structural breaks will result in a decrease in test efficacy. In order to test whether the structural breaks exist or not, Zivot-Andrews (Z-A) method is used in this paper. The outcomes of Zivot-Andrews are in Table 2.

In Table 2, the null hypothesis is accepted by all variables at level, while it is rejected by the first differences of variables. The structural breaks of $\mathrm{CO}_{2}$ emissions, per capita GDP, hydropower consumption, energy endowment,

Table 2. Zivot-Andrews unit root test

\begin{tabular}{|c|c|c|c|c|}
\hline \multirow{2}{*}{ Variable } & \multicolumn{2}{|c|}{ At level } & \multicolumn{2}{c|}{ At 1st difference } \\
\cline { 2 - 5 } & T-sta. & break & T-sta. & break \\
\hline $\ln C_{t}$ & $-3.329(4)$ & 2003 & $-5.533(4)^{\star *}$ & 2003 \\
\hline $\ln Y_{t}$ & $-3.942(2)$ & 1976 & $-7.251(1)^{\star}$ & 1982 \\
\hline $\ln Y_{t}^{2}$ & $-2.813(2)$ & 1976 & $-7.459(1)^{\star}$ & 1982 \\
\hline $\ln N_{t}$ & $-4.336(0)$ & 2004 & $-6.598(4)^{\star}$ & 2004 \\
\hline $\ln O_{t}$ & $-3.812(1)$ & 1989 & $-5.037(4)^{\star *}$ & 2002 \\
\hline $\ln S R_{t}$ & $-3.483(0)$ & 1975 & $-5.804(2)^{\star}$ & 2008 \\
\hline $\ln I S_{t}$ & $-4.154(1)$ & 1980 & $-5.637(0)^{\star}$ & 1985 \\
\hline
\end{tabular}

Note: ${ }^{*}{ }^{* *}$ and ${ }^{* * *}$ stand for the significance at $1 \%, 5 \%$ and $10 \%$ levels. fossil energy consumption and industrialization are 2003, 1976, 2004, 1975, 1989 and 1980, respectively. This suggests that there may be structural breaks in the cointegration of variables.

If the sequence has more than one structural break, the Zivot-Andrews method cannot detect the existence of other breaks, so the Bai and Perron (B-P) method is applied to test multiple structural breaks. Bai and Perron have carried out the thorough research about structural breaks and have proposed the "endogenous structure breaks test" method. This method does not need to presuppose the number and dates of structural breaks in advance, and it overcomes the limitation that only one or two structural breaks can be detected before. Bai proved that the method also has a good fit under the condition of small samples. What's more, it is an accurate and objective method at present. The findings of Bai-Perron are displayed in Table 3.

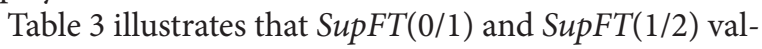
ues of $\mathrm{CO}_{2}$ emissions, economic development, fossil energy consumption and hydropower consumption are all significant at 5\% level.

The UDmax and WDmax values of these variables are also significant at $5 \%$, which confirms the existence of structural breaks, indicating that there are two structural breaks in each one of these variables. SupFT(0/1) values

Table 3. The results of Bai-Perron test

\begin{tabular}{|c|c|c|c|c|c|}
\hline Variable & $\operatorname{SupF}_{T}(0 / 1)$ & $\operatorname{SupF}_{T}(1 / 2)$ & UDmax & WDmax & Structural break \\
\hline $\ln C_{t}$ & $160.473^{*}$ & 73.890 * & $196.549^{\star}$ & $266.358^{\star}$ & 2002,1978 \\
\hline $\ln Y_{t}$ & $166.006^{*}$ & $74.156^{*}$ & $253.248^{*}$ & $343.195^{\star}$ & 1993,1980 \\
\hline $\ln Y_{t}^{2}$ & $167.893^{*}$ & $37.955^{\star}$ & $394.670^{*}$ & $341.948^{*}$ & 1995, 2006, 1984 \\
\hline $\ln N_{t}$ & $118.796^{*}$ & $114.360^{*}$ & $118.796^{*}$ & $207.832^{\star}$ & 1994,1981 \\
\hline $\ln O_{t}$ & $99.899^{*}$ & $51.280^{*}$ & $99.899^{*}$ & $194.378^{*}$ & 1992,1978 \\
\hline $\ln S R_{t}$ & $154.453^{*}$ & 8.2993 & $193.049^{*}$ & $261.614^{*}$ & 1999 \\
\hline $\ln I S_{t}$ & $217.315^{\star}$ & 0.825 & $217.315^{\star}$ & $249.480^{*}$ & 1993 \\
\hline
\end{tabular}

Note: ${ }^{\star}$ suggests significance at $5 \%$ level. 
of energy endowment and industrialization are significant at $5 \%$, while $\operatorname{SupF}_{T}(1 / 2)$ values of energy endowment and industrialization are not significant, meaning each of these variables has a structural break.

\subsection{Cointegration with structural breaks}

For studying whether there is cointegration with structural breaks or not, ARDL bounds testing is employed in this paper. The lag length selection is performed on all variables with AIC and SBC. The ARDL method with smaller error term is used in this analysis. Table 4 exhibits outcomes of ARDL method with structural breaks in series.

Table 4 illustrates that long-term links between variables exist. In N-EKC model, when carbon emissions, industrialization and hydropower consumption are expressed as independent variables and other factors are dependent variables, the F-statistics are beyond the upper bounds critical values at the significance level of $1 \%$. It illustrates the presence of cointegration with structural breaks from 1965 to 2016, meaning that long-term relations exist between the series. When economic growth, energy endowments and the square of economic growth are independent variables, the F-statistics are not significant. According to the results, there are 3 cointegration vectors in $\mathrm{N}$-EKC model. In $\mathrm{O}$-EKC model, when economic growth, carbon emissions and the square of economic growth act as independent variables, the F-statistics are significant at $1 \%$ level. It indicates that 3 cointegration vectors exist in $\mathrm{O}-\mathrm{EKC}$ model. There is no autocorrelation between error terms according to diagnostic tests. The autoregressive conditional heteroskedasticity test $\left(\chi_{A R C H}^{2}\right)$ signifies that the errors are homoscedastic. Normality test (Jarque-Bera) denotes that error terms are normally distributed. Regression setting error result presents that the models are set up very well. $\chi_{R E S E T}^{2}$ Ramsey value confirms that the models are well specified. It lustrates the existence of long-term and short-term relationships, and the effect of variables on $\mathrm{CO}_{2}$ emissions and the existence of EKC can be analyzed. The long- and short-term nexus in carbon emissions, energy endowment, economic

Table 4. The outcomes of ARDL test

\begin{tabular}{|c|c|c|c|c|c|c|}
\hline & & & & \multicolumn{3}{|c|}{ Diagnostic tests } \\
\hline Estimated N-EKC model & $\begin{array}{l}\text { Optimal lag } \\
\text { length }\end{array}$ & $\begin{array}{l}\text { Structural } \\
\text { break }\end{array}$ & F-sta. & $\chi_{A R C H}^{2}$ & $\chi_{R E S E T}^{2}$ & $\chi_{S E R I A L}^{2}$ \\
\hline$F_{\ln C_{t}}\left(\ln C_{t} / \ln Y_{t}, \ln Y_{t}^{2}, \ln S R_{t}, \ln I S_{t}, \ln N_{t}\right)$ & $(4,0,1,0,1,1)$ & 2002,1978 & $6.580^{\star}$ & $0.119[1]$ & $0.616[1]$ & $0.055[1]$ \\
\hline$F_{\ln Y_{t}}\left(\ln Y_{t} / \ln C_{t}, \ln Y_{t}^{2}, \ln S R_{t}, \ln I S_{t}, \ln N_{t}\right)$ & $(1,0,1,0,0,4)$ & 1993,1980 & 0.845 & $0.004[1]$ & $0.244[1]$ & $0.089[1]$ \\
\hline$F_{\ln Y_{t}}\left(\ln Y_{t t}^{2} / \ln C_{t}, \ln Y, \ln S R_{t}, \ln I S_{t}, \ln N_{t}\right)$ & $(2,0,1,0,0,0)$ & $\begin{array}{l}1995,2006 \\
1984\end{array}$ & 0.560 & $2.988[1]$ & $2.923[1]$ & $0.453[1]$ \\
\hline$F_{\ln S R_{t}}\left(\ln S R_{t} / \ln Y_{t}, \ln Y_{t}^{2}, \ln C_{t}, \ln I S_{t}, \ln N_{t}\right)$ & $(1,0,1,1,0,0)$ & 1999 & 2.384 & $2.726[1]$ & $2.666[1]$ & $1.030[1]$ \\
\hline$F_{\ln I S_{t}}\left(\ln I S_{t} / \ln Y_{t}, \ln Y_{t}^{2}, \ln S R_{t}, \ln C_{t}, \ln N_{t}\right)$ & $(3,1,0,0,1,2)$ & 1993 & $7.581^{\star}$ & $1.668[1]$ & $9.165[1]$ & $0.189[1]$ \\
\hline$F_{\ln N_{t}}\left(\ln N_{t} / \ln Y_{t}, \ln Y_{t}^{2}, \ln S R_{t}, \ln I S_{t}, \ln C_{t}\right)$ & $(1,1,0,0,0,0)$ & 1994,1981 & $7.004^{*}$ & $1.591[1]$ & $6.083[1]$ & $0.151[1]$ \\
\hline Estimated O-EKC model & $\begin{array}{c}\text { Optimal lag } \\
\text { length }\end{array}$ & $\begin{array}{l}\text { Structural } \\
\text { break }\end{array}$ & F-sta. & $\chi_{A R C H}^{2}$ & $\chi_{R E S E T}^{2}$ & $\chi_{S E R I A L}^{2}$ \\
\hline$F_{\ln C_{t}}\left(\ln C_{t} / \ln Y_{t}, \ln Y_{t}^{2}, \ln S R_{t}, \ln I S_{t}, \ln O_{t}\right)$ & $(1,0,1,0,0,1)$ & 2002,1978 & $5.170^{\star *}$ & $8.193[1]$ & $0.899[1]$ & $0.809[1]$ \\
\hline$F_{\ln Y_{t}}\left(\ln Y_{t} / \ln C_{t}, \ln Y_{t}^{2}, \ln S R_{t}, \ln I S_{t}, \ln O_{t}\right)$ & $(1,1,1,0,0,0)$ & 1993,1980 & $18.323^{*}$ & $0.354[1]$ & $1.841[1]$ & $0.222[1]$ \\
\hline$F_{\ln Y_{t}}\left(\ln Y_{t t}^{2} / \ln C_{t}, \ln Y, \ln S R_{t}, \ln I S_{t}, \ln O_{t}\right)$ & $(1,0,1,1,0,0)$ & $\begin{array}{l}1995,2006 \\
1984\end{array}$ & $7.765^{\star}$ & $0.029[1]$ & $2.693[1]$ & $1.700[1]$ \\
\hline$F_{\ln S R_{t}}\left(\ln S R_{t} / \ln Y_{t}, \ln Y_{t}^{2}, \ln C_{t}, \ln I S_{t}, \ln O_{t}\right)$ & $(1,0,1,1,0,0)$ & 1999 & 2.971 & $0.122[1]$ & $0.513[1]$ & $0.321[1]$ \\
\hline$F_{\ln I S_{t}}\left(\ln I S_{t} / \ln Y_{t}, \ln Y_{t}^{2}, \ln S R_{t}, \ln C_{t}, \ln O_{t}\right)$ & $(1,1,1,0,0,0)$ & 1993 & 2.329 & $0.610[1]$ & $4.519[1]$ & $2.205[1]$ \\
\hline$F_{\ln O_{t}}\left(\ln O_{t} / \ln Y_{t}, \ln Y_{t}^{2}, \ln S R_{t}, \ln I S_{t}, \ln C_{t}\right)$ & $(1,1,0,0,0,0)$ & 1992,1978 & 3.471 & $0.501[1]$ & $1.049[1]$ & $0.138[1]$ \\
\hline \multirow[t]{2}{*}{ Significant level } & \multicolumn{3}{|c|}{ Critical values $(\mathrm{T}=52)^{\#}$} & & & \\
\hline & \multicolumn{3}{|c|}{ Lower bounds I(0) } & \multicolumn{3}{|c|}{ Upper bounds I(1) } \\
\hline $1 \%$ level & \multicolumn{3}{|c|}{3.955} & \multicolumn{3}{|c|}{5.583} \\
\hline $5 \%$ level & \multicolumn{3}{|c|}{2.900} & \multicolumn{3}{|c|}{4.218} \\
\hline $10 \%$ level & \multicolumn{3}{|c|}{2.435} & \multicolumn{3}{|c|}{3.600} \\
\hline
\end{tabular}

Note: ${ }^{\star},{ }^{* *},{ }^{* *}$ represent significance at $1 \%, 5 \%$ and $10 \%$ levels. 
growth, hydropower consumption, industrialization and fossil energy consumption are shown in Table 5.

First of all, we can see that both in O-EKC and NEKC models, the long-run coefficients of $\ln Y_{t}$ and $\ln Y_{t}^{2}$ are positive and negative. The findings demonstrate that there is EKC in China. The result is consistent with Alam, Murad, Noman, and Ozturk (2016). Based on the study of long-term relationship, it is found that in N-EKC model, the coefficient of hydropower consumption is negative, indicating that hydropower consumption increases $1 \%$, and carbon emissions will be reduced by $0.155 \%$.

In O-EKC model, fossil energy consumption coefficient is positive, which means that it increases carbon emissions, that is, with other variables constant, a $1 \%$ rise in fossil energy consumption increases $0.843 \%$ of carbon emissions. It boots carbon emissions by $0.614 \%$ when economic growth rises $1 \%$. The outcomes of this study are consistent with Abdulkadir (2016). The square of economic growth is in negative relation with the carbon emissions, and when the other conditions are unchanged, the square of economic growth is increased by $1 \%$ and the carbon emissions is reduced by $0.042 \%$. Economic growth positively influents carbon emissions and the square of economic growth negatively affects carbon emissions under the condition of structural breaks. The impact of hydropower on $\mathrm{CO}_{2}$ emission is increasing, since the absolute value of long-term coefficient of $\ln N_{t}$ is greater than that of short-term. The difference value of $\ln O_{t}$ coefficient is smaller than that of $\ln N_{t}$. This illustrates that fossil energy contributes to carbon emission; however, its influence will be weakened over time and hydropower will increasingly decrease carbon emissions.

From short-run coefficients, in N-EKC model, economic growth and industrialization positively affect carbon emissions. They lead to carbon emissions increase by $0.004 \%$ and $0.198 \%$ when economic growth and industrialization increase $1 \%$. The square of economic growth, hydropower consumption and energy endowments negatively affect carbon emissions. A $1 \%$ decrease in economic development, hydropower consumption and energy endowments decrease carbon emissions by $0.031 \%, 0.042 \%$ and $0.096 \%$, respectively. The coefficient of ECMt- 1 is
-0.129. In O-EKC model, economic growth, fossil energy consumption and industrialization show great favorable influence on carbon emissions. What's more, the square of economic growth and energy endowment have a negative contribution to carbon emissions. The value of ECMt- 1 is equivalent to -0.248 . It is statistically significant and further validates that each variable has a definite long-term relationship.

\subsection{VECM Granger causality test considering structural breaks}

The causality relation among the sequences is analyzed and Table 6 presents the long- and short-term outcomes. In N-EKC model, the long-term coefficients, -0.123 and -0.047 , are significant. It illustrates that causality between $\mathrm{CO}_{2}$ emissions and economic growth are bidirectional. This finding coincides with Zhang, Pang, Chen, and Lu (2019). According to the analysis, since the coefficients, $-0.123,-0.047$ and -0.052 , are significant, there is evidence of bidirectional Granger causality among industrialization level, carbon emissions and economic growth. This discovery is the same as Rahman and Kashem (2017). According to long-run and strong causality results, bidirectional causality is between $\mathrm{CO}_{2}$ emissions and hydropower consumption, hydropower consumption and economic growth, industrialization level and hydropower consumption. This result is supporting the prior study of Bildirici and Gökmenoğlu (2017). Bidirectional linkages exist between fossil energy consumption and carbon emissions, fossil energy consumption and economic growth, and fossil energy consumption and industrialization level. The findings are similar to that of Pinzón (2018).

In a very short period, the coefficients of economic growth and energy endowment are 9.433 and 5.887, significant in levels of $1 \%$ and $10 \%$, respectively. Unidirectional causal relation is from economic growth to $\mathrm{CO} 2$ emissions, energy endowment to carbon emissions. Economic growth Granger causes energy endowment, just as industrialization level to energy endowment. Bidirectional nexus is between Hydropower consumption and carbon emissions. The bidirectional Granger causality exists between industrialization level and carbon emission,

Table 5. Estimation of long-term and short-term nexus

\begin{tabular}{|c|c|c|c|c|c|c|c|c|c|}
\hline \multicolumn{10}{|c|}{ Long-run } \\
\hline Variable & $\ln Y_{t}$ & $\ln Y_{t}^{2}$ & $\ln N_{t}$ & $\ln O_{t}$ & $\ln S R_{t}$ & $\ln I S_{t}$ & Constant & D2002 & D1978 \\
\hline Coef. & $0.129^{*}$ & $-0.012^{*}$ & $-0.155^{\star}$ & - & $3.793^{\star *}$ & $1.544^{\star}$ & $-8.932^{\star}$ & $0.758^{\star}$ & $-0.150^{\star}$ \\
\hline Coef. & $0.164^{*}$ & $-0.006^{*}$ & - & $0.843^{\star}$ & $0.137^{\star \star}$ & $0.134^{*}$ & $-1.239^{* *}$ & $0.251^{\star}$ & $-0.046^{\star}$ \\
\hline \multicolumn{10}{|c|}{ Short-run } \\
\hline Variable & $\Delta \ln Y_{t}$ & $\Delta \ln Y_{t}^{2}$ & $\Delta \ln N_{t}$ & $\Delta \ln O_{t}$ & $\Delta \ln S R_{t}$ & $\Delta \ln I S_{t}$ & $\Delta \mathrm{D} 2002$ & $\Delta \mathrm{D} 1978$ & $\operatorname{ECM}(-1)$ \\
\hline Coef. & $0.004^{*}$ & $-0.031^{\star}$ & $-0.042^{\star}$ & - & $-0.096^{*}$ & $0.198^{\star *}$ & 0.097 & $-0.019^{\star}$ & $-0.129^{*}$ \\
\hline Coef. & $0.152^{*}$ & $-0.007^{\star}$ & - & $0.773^{\star}$ & $-0.034^{\star}$ & $0.033^{*}$ & $0.062^{*}$ & $-0.012^{\star}$ & $-0.248^{\star}$ \\
\hline
\end{tabular}

Note: ${ }^{*},{ }^{* \star},{ }^{* \star}$ are significant at $1 \%, 5 \%$ and $10 \%$ levels. 
Table 6. VECM Granger causality results

\begin{tabular}{|c|c|c|c|c|c|c|c|}
\hline \multicolumn{8}{|c|}{ Independent variable } \\
\hline \multirow[t]{2}{*}{ N-EKC model } & \multicolumn{5}{|c|}{ Short-term } & \multicolumn{2}{|c|}{ Long-term } \\
\hline & $\sum \Delta \ln C_{t-1}$ & $\sum \Delta \ln Y_{t-1}$ & $\sum \Delta \ln Y_{t-1}^{2}$ & $\sum \Delta \ln N_{t-1}$ & $\sum \Delta \ln S R_{t-1}$ & $\sum \Delta \ln I S_{t-1}$ & $E C T_{t-1}$ \\
\hline$\Delta \ln C_{t}$ & - & $9.433^{\star}$ & $8.555^{\star \star}$ & $18.039^{\star}$ & $5.887^{\star \star \star}$ & $8.636^{\star}$ & $-0.123^{\star}$ \\
\hline$\Delta \ln Y_{t}$ & 1.749 & - & $7.627^{\star *}$ & 4.074 & 0.919 & $9.541^{*}$ & $-0.047^{*}$ \\
\hline$\Delta \ln Y_{t}^{2}$ & 0.601 & $6.767^{\star *}$ & - & 3.426 & 0.504 & $9.039^{*}$ & $-0.761^{\star}$ \\
\hline$\Delta \ln N_{t}$ & $5.328^{* * *}$ & 2.507 & 3.828 & - & 1.703 & $5.536^{\star * *}$ & $-0.071^{\star}$ \\
\hline$\Delta \ln S R_{t}$ & 1.127 & $6.204^{\star *}$ & $8.227^{\star *}$ & 4.005 & - & $8.618^{\star *}$ & 0.007 \\
\hline$\Delta \ln I S_{t}$ & $9.630^{*}$ & $9.008^{\star *}$ & $8.126^{\star *}$ & $6.151^{* *}$ & 0.132 & - & $-0.052^{\star *}$ \\
\hline O-EKC model & $\sum \Delta \ln C_{t-1}$ & $\sum \Delta \ln Y_{t-1}$ & $\sum \Delta \ln Y_{t-1}^{2}$ & $\sum \Delta \ln O_{t-1}$ & $\sum \Delta \ln S R_{t-1}$ & $\sum \Delta \ln I S_{t-1}$ & $E C T_{t-1}$ \\
\hline$\Delta \ln C_{t}$ & - & $9.480^{\star *}$ & $9.093^{\star *}$ & $20.487^{\star}$ & 2.775 & $10.542^{\star}$ & $-1.028^{*}$ \\
\hline$\Delta \ln Y_{t}$ & $24.512^{\star}$ & - & $28.138^{\star}$ & $16.771^{*}$ & $10.058^{\star *}$ & $9.418^{*}$ & $-1.011^{\star}$ \\
\hline$\Delta \ln Y_{t}^{2}$ & $19.258^{\star}$ & $21.674^{*}$ & - & $14.289^{*}$ & $7.526^{\star * *}$ & $10.478^{\star}$ & $-11.484^{*}$ \\
\hline$\Delta \ln O_{t}$ & $47.703^{\star}$ & $11.543^{\star}$ & $12.460^{\star}$ & - & $7.309^{* * *}$ & 5.043 & $-1.161^{\star}$ \\
\hline$\Delta \ln S R_{t}$ & 1.435 & 0.787 & 0.278 & $9.458^{\star}$ & - & 3.685 & 0.151 \\
\hline$\Delta \ln I S_{t}$ & $12.125^{\star}$ & $17.282^{\star}$ & $18.605^{\star}$ & $11.825^{\star}$ & 2.812 & - & $-0.991^{*}$ \\
\hline
\end{tabular}

Note: ${ }^{*}{ }^{* *}$ and ${ }^{* *}$ are significant at $1 \%, 5 \%$ and $10 \%$ levels.

industrialization level and economic growth. Industrialization level Granger causes hydropower consumption and as a result, hydropower consumption Granger causes industrialization level.

\section{Further discussion}

The absolute values of long-term coefficients of fossil energy consumption and hydropower consumption are greater than that of short-term coefficients. The results suggest that as time goes on, the consumption of hydropower will decrease $\mathrm{CO}_{2}$ emissions increasingly significant. And at the same time, it also reflects that $\mathrm{CO}_{2}$ emissions from fossil energy consumption will continue to rise for some time. Notably, the absolute value of hydropower consumption coefficient is far lower than that of fossil energy consumption, which means that the reduction of carbon emissions from hydropower consumption can be masked because of the increase of fossil energy consumption.

\section{Conclusions and policy implications}

Based on the EKC hypothesis, two models were constructed by introducing fossil energy consumption, hydropower consumption, industrialization level and energy endowment, and the effect of these factors on carbon emissions from 1965 to 2016 was analyzed. The unit root tests were carried out to estimate the stability of variables. The ARDL method with structural breaks was used to explore the cointegration and long- and short-term dynamic relations between variables in the two models. The causal relationship and direction between the variables in the two models are analyzed by VECM Granger causality. It is found that long-term cointegration relationships exist when carbon emissions variable is an independent variable. Industrialization, $\mathrm{CO}_{2}$ emissions, economic growth and hydropower (fossil) energy consumption all have long-term bidirectional granger causality. The main conclusions are as follows.

1. The results reflect that EKC exists in China. The long-term coefficients of $\ln Y_{t}$ and $\ln Y_{t}^{2}$ both in N-EKC and O-EKC models are positive and negative, respectively. This suggests that economic growth deepens over time, and $\mathrm{CO}_{2}$ emissions in China will reach a peak and then shows a downtrend. The result is consistent with the study of Li, Wang, and Zhao (2016).

2. The ARDL estimation outcomes reveal that $\mathrm{CO}_{2}$ emissions can be significantly reduced by the consumption of hydropower in China. And as time goes on, the consumption of hydropower will decrease $\mathrm{CO}_{2}$ emissions more and more significantly. Specifically, carbon emissions will be reduced by $0.155 \%$ when hydropower consumption increase $1 \%$, which means that hydropower can become an effective alternative for fossil energy. The absolute value of long-run coefficient of $\ln N_{t}$ is 0.155 , which is greater than short-run coefficient of $\ln N_{t}, 0.042$. The outcome is in line with Ogino, Dash, and Nakayama (2019). 
3. The VECM Granger causality outcomes indicate that many factors have bidirectional causal links with $\mathrm{CO}_{2}$ emissions. Industrialization level and economic growth have bidirectional relationships with $\mathrm{CO}_{2}$ emissions. This reveals that the increase of industrialization level and economic growth results in an increase in $\mathrm{CO}_{2}$ emissions. For another, $\mathrm{CO}_{2}$ emissions can affect industrialization level and economic growth. The outcomes are similar with the prior study of Muhammad (2019).

Based on the above conclusions, important policy implications are proposed.

1. More attention should be payed to formulate economic, environmental and energy policies to promote the EKC research in China (Xie, Xu, \& Liu, 2019).

2. Since the reduction of $\mathrm{CO}_{2}$ emissions from hydropower consumption can be masked by the increase of fossil energy consumption, a series of policies are supposed to be adopted to increase the share of hydropower consumption, and increase other clean energies (Bello, Sakiru, \& Yuen, 2018).

3. Economic transformation should be promoted to renewable energy. Policies should be formulated to reduce $\mathrm{CO}_{2}$ emissions, and at the same time increase economic growth (Mikayilov, Galeotti, \& Hasanov, 2018).

\section{Acknowledgements}

This research was funded by Key Program of the National Social Science Foundation of China [grant number 18AGL028]; Social Science Foundation of the Higher Education Institutions of Jiangsu Province, China [grant number 2018SJZDI070]; Social Science Foundations of Jiangsu Province, China [grant numbers 16ZZB004, 17ZTB005].

\section{References}

Abdulkadir, A. (2016). Does the need for economic growth influence energy consumption and $\mathrm{CO}_{2}$ emissions in Nigeria? Evidence from the innovation accounting test. Renewable and Sustainable Energy Reviews, 62, 1209-1225.

https://doi.org/10.1016/j.rser.2016.05.028

Arestis, P., \& Baltar, C. T. (2019). A model of economic growth for an open emerging country: empirical evidence for Brazil. Structural Change and Economic Dynamics, 49, 217-227. https://doi.org/10.1016/j.strueco.2018.10.005

Alam, M. M., Murad, M. W., Noman, A. H. M., \& Ozturk, I. (2016). Relationships among carbon emissions, economic growth, energy consumption and population growth: testing Environmental Kuznets Curve hypothesis for Brazil, China, India and Indonesia. Ecological Indicator, 70, 466-479. https://doi.org/10.1016/j.ecolind.2016.06.043

Bai, J., \& Perron, P. (2003). Computation and analysis of multiple structural change models. Cahiers de Recherche, 18, 1-22. https://doi.org/10.1002/jae.659

Balado-Naves, R., Baños-Pino, J. F., \& Mayor, M. (2018). Do countries influence neighbouring pollution? A spatial analysis of the EKC for CO emissions. Energy Policy, 123, 266-279. https://doi.org/10.1016/j.enpol.2018.08.059

Bimonte, S., \& Stabile, A. (2017). Land consumption and income in Italy: a case of inverted EKC. Ecological Economics, 131, 3643. https://doi.org/10.1016/j.ecolecon.2016.08.016
Bekhet, H. A., \& Othman, N. S. (2018). The role of renewable energy to validate dynamic interaction between $\mathrm{CO}_{2}$ emissions and GDP toward sustainable development in Malaysia. Energy Economics, 72, 47-61.

https://doi.org/10.1016/j.eneco.2018.03.028

Bhattacharya, M., Churchill, S. A., \& Paramati, S. R. (2017). The dynamic impact of renewable energy and institutions on economic output and $\mathrm{CO}_{2}$ emissions across regions. Renewable Energy, 111, 157-167.

https://doi.org/10.1016/j.renene.2017.03.102

Bian, N., \& Yu, H. W. (2019). How does energy endowment and technological progress affect carbon emission intensity? An empirical analysis based on China's Yangtze River economic zone. Ekoloji Dergisi, 28, 3991-4002.

Bernier, M., \& Plouff, M. (2019). Financial innovation, economic growth, and the consequences of macroprudential policies. Research in Economics, 73, 162-173. https://doi.org/10.1016/j.rie.2019.04.003

Bello, M. O., Sakiru, A. S., \& Yuen, Y. Y. (2018). The impact of electricity consumption on $\mathrm{CO}_{2}$ emission, carbon footprint, water footprint and ecological footprint: the role of hydropower in an emerging economy. Journal of Environmental Management, 219, 218-230.

https://doi.org/10.1016/j.jenvman.2018.04.101

Bildirici, M. E., \& Gökmenoğlu, S. M. (2017). Environmental pollution, hydropower energy consumption and economic growth: Evidence from G7 countries. Renewable and Sustainable Energy Reviews, 75, 68-85. https://doi.org/10.1016/j.rser.2016.10.052

BP. (2018). BP Statistical Review of Word Energy 2018. Retrieved from https://www.bp.com/en/global/corporate/energyeconomics/statistical-review-of-world-energy.html

CSY. (2018). China statistical yearbook. Retrieved from http:// www.stats.gov.cn/tjsj/ndsj/2018/indexch.htm

CESY. (2017). China energy statistical yearbook. Retrieved from http://www.stats.gov.cn/tjsj/tjcbw/201806/t20180612_ 1604117.html

Dong, B., Wang, F., \& Guo, Y. (2016). The global EKCs. International Review of Economics \& Finance, 43, 210-221. https://doi.org/10.1016/j.iref.2016.02.010

Dong, K., Sun, R., \& Dong, X. (2018). $\mathrm{CO}_{2}$ emissions, natural gas and renewables, economic growth: assessing the evidence from China. Science of the Total Environment, 640-641, 293302. https://doi.org/10.1016/j.scitotenv.2018.05.322

Dong, C., Dong, X., Jiang, Q., Dong, K., \& Liu, G. (2018). What is the probability of achieving the carbon dioxide emission targets of the Paris agreement? Evidence from the top ten emitters. Science of the Total Environment, 622, 1294-1303. https://doi.org/10.1016/j.scitotenv.2017.12.093

Danish, Zhang, B., Wang, B., \& Wang, Z. (2017). Role of renewable energy and non-renewable energy consumption on EKC: Evidence from Pakistan. Journal of Cleaner Production, 156, 855-864. https://doi.org/10.1016/j.jclepro.2017.03.203

Du, Q., Shao, L., Zhou, J., Huang, N., Bao, T., \& Hao, C. C. (2019). Dynamics and scenarios of carbon emissions in China's construction industry. Sustainable Cities and Society, 48, 101556. https://doi.org/10.1016/j.scs.2019.101556

Gill, A. R., Viswanathana, K. K., \& Hassanb, S. (2018). The Environmental Kuznets Curve (EKC) and the environmental problem of the day. Renewable and Sustainable Energy Reviews, $81,1636-1642$. https://doi.org/10.1016/j.rser.2017.05.247

Ghaffar, A., Ashraf, A., Bashir, M. K., \& Cui, S. H. (2017). Exploring environmental Kuznets curve (EKC) in relation to green 
revolution: a case study of Pakistan. Environmental Science \& Policy, 77, 166-171.

https://doi.org/10.1016/j.envsci.2017.08.019

Gasparatos, A., Doll, C., Esteban, M., Ahmed, A., \& Olang, T. A. (2017). Renewable energy and biodiversity: implications for transitioning to a Green Economy. Renewable and Sustainable Energy Reviews, 70, 161-184.

https://doi.org/10.1016/j.rser.2016.08.030

Haraguchi, N., Martorano, B., \& Sanfilippo, M. (2019). What factors drive successful industrialization? Evidence and implications for developing countries. Structural Change and Economic Dynamics, 49, 266-276. https://doi.org/10.1016/j.strueco.2018.11.002

Kasman, A., \& Duman, Y. S. (2015). $\mathrm{CO}_{2}$ emissions, economic growth, energy consumption, trade and urbanization in new EU member and candidate countries: a panel data analysis. Economic Modelling, 44, 97-103.

https://doi.org/10.1016/j.econmod.2014.10.022

Kousksou, T., Allouhi, A., Belattar, M., Jamil, A., Rhafiki, T. E., \& Zeraouli, Y. (2015). Morocco's strategy for energy security and low-carbon growth. Energy, 84, 98-105.

https://doi.org/10.1016/j.energy.2015.02.048

Liu, X., Zhang, S., \& Bae, J. (2017). The impact of renewable energy and agriculture on carbon dioxide emissions: investigating the environmental Kuznets curve in four selected ASEAN countries. Journal of Cleaner Production, 164, 12391247. https://doi.org/10.1016/j.jclepro.2017.07.086

Li, K., \& Lin, B. Q. (2015). Impacts of urbanization and industrialization on energy consumption $/ \mathrm{CO}_{2}$ emissions: does the level of development matter? Renewable and Sustainable Energy Reviews, 52, 1107-1122.

https://doi.org/10.1016/j.rser.2015.07.185

Li, T., Wang, Y., \& Zhao, D. (2016). Environmental Kuznets Curve in China: new evidence from dynamic panel analysis. Energy Policy, 91, 138-147. https://doi.org/10.1016/j.enpol.2016.01.002

Muhammad, B. (2019). Energy consumption, $\mathrm{CO}_{2}$ emissions and economic growth in developed, emerging and Middle East and North Africa countries. Energy, 179, 232-245.

https://doi.org/10.1016/j.energy.2019.03.126

Muhammad, S., Mantu, K. M., Syed, J. H., \& Shawkat, H. (2019). Testing the globalization-driven carbon emissions hypothesis: International evidence. International Economics, 158, 25-38. https://doi.org/10.1016/j.inteco.2019.02.002

Mohamed, H., Jebli, M. B., \& Youssef, S. B. (2019). Renewable and fossil energy, terrorism, economic growth, and trade: Evidence from France. Renewable Energy, 139, 459-467. https://doi.org/10.1016/j.renene.2019.02.096

Meng, M., Fu, Y. N., \& Wang, X. F. (2018). Decoupling, decomposition and forecasting analysis of China's fossil energy consumption from industrial output. Journal of Cleaner Production, $177,752-759$.

https://doi.org/10.1016/j.jclepro.2017.12.278

Mikayilov, J. I., Galeotti, M., \& Hasanov, F. J. (2018). The impact of economic growth on $\mathrm{CO}_{2}$ emissions in Azerbaijan. Journal of Cleaner Production, 197, 1558-1572. https://doi.org/10.1016/j.jclepro.2018.06.269

Ngarambe, J., Lim, H. S., \& Kim, G. (2018). Light pollution: Is there an Environmental Kuznets Curve? Sustainable Cities and Society, 42, 337-343. https://doi.org/10.1016/j.scs.2018.07.018

Ogino, K., Dash, S. K., \& Nakayama, M. (2019). Change to hydropower development in Bhutan and Nepal. Energy for Sustainable Development, 50, 1-17.

https://doi.org/10.1016/j.esd.2019.02.005
Pata, U. (2018). Renewable energy consumption, urbanization, financial development, income and $\mathrm{CO}_{2}$ emissions in Turkey: Testing EKC hypothesis with structural breaks. Journal of Cleaner Production, 187, 770-779.

https://doi.org/10.1016/j.jclepro.2018.03.236

Pesaran, M. H., Shin, Y., \& Smith, R. J. (2001). Bounds testing approaches to the analysis of level relationships. Journal of Applied Econometrics, 16, 289-326.

https://doi.org/10.1002/jae.616

Pinzón, K. (2018). Dynamics between energy consumption and economic growth in Ecuador: A granger causality analysis. Economic Analysis and Policy, 57, 88-101. https://doi.org/10.1016/j.eap.2017.09.004

Rafindadi, A. A., \& Ozturk, I. (2016). Effects of financial development, economic growth and trade on electricity consumption: evidence from post-Fukushima Japan. Renewable and Sustainable Energy Reviews, 54, 1073-1084. https://doi.org/10.1016/j.rser.2015.10.023

Rahman, M. M., \& Kashem, M. A. (2017). Carbon emissions, energy consumption and industrial growth in Bangladesh: Empirical evidence from ARDL cointegration and Granger causality analysis. Energy Policy, 110, 600-608. https://doi.org/10.1016/j.enpol.2017.09.006

Shabani, Z. D., \& Shahnazi, R. (2019). Energy consumption, carbon dioxide emissions, information and communications technology, and gross domestic product in Iranian economic sectors: A panel causality analysis. Energy, 169, 1064-1078. https://doi.org/10.1016/j.energy.2018.11.062

Seker, F., Ertugrul, H. M., \& Cetin, M. (2015). The impact of foreign direct investment on environmental quality: A bounds testing and causality analysis for Turkey. Renewable and Sustainable Energy Reviews, 52, 347-356. https://doi.org/10.1016/j.rser.2015.07.118

Ulucak, R., \& Bilgili, F. (2018). A reinvestigation of EKC model by ecological footprint measurement for high, middle and low income countries. Journal of Cleaner Production, 188, 144-157. https://doi.org/10.1016/j.jclepro.2018.03.191

Wang, Y. P., Yan, W. L., Zhuang, S. W., \& Zhang, Q. (2019). Competition or complementarity? The hydropower and thermal power nexus in China. Renewable Energy, 138, 531-541. https://doi.org/10.1016/j.renene.2019.01.130

Xie, Q. H., Xu, X., \& Liu, X. Q. (2019). Is there an EKC between economic growth and smog pollution in China? New evidence from semiparametric spatial autoregressive models. Journal of Cleaner Production, 220, 873-883. https://doi.org/10.1016/j.jclepro.2019.02.166

Zhang, B., Wang, B., \& Wang, Z. (2017). Role of renewable energy and non-renewable energy consumption on EKC: evidence from Pakistan. Journal of Cleaner Production, 156, 855-864. https://doi.org/10.1016/j.jclepro.2017.03.203

Zhang, L., Pang, J. X., Chen, X. P., \& Lu, Z. (2019). Carbon emissions, energy consumption and economic growth: Evidence from the agricultural sector of China"s main grain-producing areas. Science of The Total Environment, 665, 1017-1025. https://doi.org/10.1016/j.scitotenv.2019.02.162

Zhong, R., Zhao, T. G., He, Y. H., \& Chen, X. H. (2019). Hydropower change of the water tower of Asia in 21st century: A case of the Lancang River hydropower base, upper Mekong. Energy, 179, 685-696. https://doi.org/10.1016/j.energy.2019.05.059

Zhou, K., \& Li, Y. W. (2019). Influencing factors and fluctuation characteristics of China's carbon emission trading price. Physica A: Statistical Mechanics and its Applications, 524, 459474. https://doi.org/10.1016/j.physa.2019.04.249 
Zhou, X. X., \& Feng, C. (2017). The impact of environmental regulation on fossil energy consumption in China: Direct and indirect effects. Journal of Cleaner Production, 142, 3174-

3183. https://doi.org/10.1016/j.jclepro.2016.10.152

\section{APPENDIX}

\section{Supplementary data}

Table A1. Definition of the variables

\begin{tabular}{|l|l|l|l|l|}
\hline \multicolumn{1}{|c|}{ Variable } & \multicolumn{1}{|c|}{ Definition } & \multicolumn{1}{c|}{ Unit } & \multicolumn{1}{c|}{ Supporting reference } & \multicolumn{1}{c|}{ Data source } \\
\hline SR & Energy endowment & $\%$ & $\begin{array}{l}\text { Rafindadi and Ozturk (2016); Bian and Yu } \\
(2019)\end{array}$ & CESY (2017) \\
\hline IS & Industrialization level & $\%$ & Haraguchi et al. (2019); Li and Lin (2015) & CSY, (2018) \\
\hline C & Carbon emissions & Per capita/tons & Zhou and Li (2019); Du et al., (2019) & BP (2018); CSY (2018) \\
\hline GDP & Economic growth & Per capita/yuan & $\begin{array}{l}\text { Arestis and Baltar (2019); Bernier and } \\
\text { Plouff (2019) }\end{array}$ & CSY (2018) \\
\hline N & $\begin{array}{l}\text { Hydropower } \\
\text { consumption }\end{array}$ & Mtoe & $\begin{array}{l}\text { Zhong Zhao, He, and Chen, (2019); Wang, } \\
\text { Yan, Zhuang, and Zhang (2019) }\end{array}$ & $\begin{array}{l}\text { CESY (2017); } \\
\text { CSY (2018) }\end{array}$ \\
\hline O & $\begin{array}{l}\text { Fossil energy } \\
\text { consumption }\end{array}$ & Mtoe & $\begin{array}{l}\text { Meng, Fu, \& Wang (2018); Zhou and Feng } \\
(2017)\end{array}$ & CESY (2017) \\
\hline
\end{tabular}

Table A2. Meaning of the abbreviations in this paper

\begin{tabular}{|l|l|l|l|}
\hline \multicolumn{1}{|c|}{ ARDL } & \multicolumn{1}{|c|}{ Autoregressive distributed lag model } & \multicolumn{1}{c|}{ GDP } & \multicolumn{1}{c|}{ Gross domestic product (Economic growth) } \\
\hline AIC & Akaike information criteria & IS & industrialization level \\
\hline ADF & Augmented Dickey-Fuller & Mtoe & million tonnes oil equivalent \\
\hline B-P & Bai and Perron method & N & Hydropower consumption \\
\hline BP & formerly British Petroleum & N-EKC & $\begin{array}{l}\text { the EKC model that considers the role of hydropower } \\
\text { consumption }\end{array}$ \\
\hline CESY & China Energy Statistical Yearbook & O-EKC & $\begin{array}{l}\text { the EKC model that considers the role of fossil energy } \\
\text { consumption }\end{array}$ \\
\hline CSY & China Statistical Yearbook & O & Fossil energy consumption \\
\hline CO ${ }_{2}(\mathrm{C})$ & Carbon dioxide & PP & Phillips-Perron \\
\hline$D_{1}$ & dummy variable & SR & Energy endowment \\
\hline$D_{2}$ & dummy variables & SBC & Schwarz-Bayesian criteria \\
\hline DF-GLS & Dickey-Fuller Generalized Least Squares & Sup-F test & Sup wald test \\
\hline EKC & The environmental kuznets curve & VECM & vector error correction model \\
\hline FMOLS & Fully modified ordinary least squares & Z-A & Zivot-Andrews method \\
\hline
\end{tabular}

Table A3. Descriptive statistics of the selected variables

\begin{tabular}{|l|c|c|c|c|c|c|}
\hline & $\ln C$ & $\ln Y$ & $\ln$ & $\ln$ & $\ln I S$ & $\operatorname{lnSR}$ \\
\hline Mean & 0.79 & 7.60 & -3.60 & -0.16 & 3.87 & 4.58 \\
\hline Median & 0.73 & 7.43 & -3.70 & -0.18 & 3.85 & 4.60 \\
\hline Max. & 1.91 & 9.62 & -1.67 & 1.02 & 4.13 & 4.71 \\
\hline Min. & -0.50 & 5.95 & -5.16 & -1.49 & 3.44 & 4.37 \\
\hline Std. Dev. & 0.70 & 1.16 & 1.02 & 0.71 & 0.20 & 0.09 \\
\hline Skewness & 0.09 & 0.24 & 0.31 & 0.01 & -0.18 & -0.46 \\
\hline Kurtosis & -0.83 & -1.26 & -0.95 & -0.76 & -1.20 & -0.99 \\
\hline
\end{tabular}

